\title{
THREE-DIMENSIONAL OBSERVATIONS ON THICK BIOLOGICAL SPECIMENS BY HIGH VOLTAGE ELECTRON MICROSCOPY
}

\author{
TETSUJI NAGATA
}

Department of Anatomy and Cell Biology, Shinshu University School of Medicine, Matsumoto 390-8621, and Department of Anatomy and Physiology, Nagano Women' s Jr. College, Nagano, 380-0803, Japan (Accepted January 20, 2000)

\begin{abstract}
Thick biological specimens prepared as whole mount cultured cells or thick sections from embedded tissues were stained with histochemical reactions, such as thiamine pyrophosphatase, glucose-6-phosphatase, cytochrome oxidase, acid phosphatase, DAB reactions and radioautography, to observe 3-D ultrastructures of cell organelles producing stereo-pairs by high voltage electron microscopy at accerelating voltages of $400-1000 \mathrm{kV}$. The organelles demonstrated were Golgi apparatus, endoplasmic reticulum, mitochondria, lysosomes, peroxisomes, pinocytotic vesicles and incorporations of radioactive compounds. As the results, those cell organelles were observed 3dimensionally and the relative relationships between these organelles were demonstrated.
\end{abstract}

Keywords: 3-D observation, cell organelles, high voltage electron microscopy, histochemistry, thick specimens.

\section{INTRODUCTION}

In order to demonstrate 3-dimensional structure of cell organelles in thick biological specimens, we have observed both whole mount cultured cells and thick sections obtained from embedded tissues which were stained with various histochemical reactions for specific cell organelles by high voltage electron microscopy at accerelating voltages of $400-1000 \mathrm{kV}$ (Nagata et al., 1977, 1986, 1987, 1990; Nagata, 1995, 1997). This paper deals with the results obtained by observing whole mount cultured cells and thick sections from embedded tissues which were stained with several histochemical reactions demonstrating respective cell organelles.

\section{MATERIALS AND METHODS}

Cultured cells used were both primary culture and established cell lines. The liver tissues of adult Wistar rats were isolated by collagenase perfusion. The isolated hepatocytes were suspended in Leibovitz L-15 medium and seeded on formval coated gold meshes in Petri dishes (Falcon Plastic, USA), which were incubated in a $\mathrm{CO}_{2}$ incubator (Tabai, Tokyo, Japan) in a humidified atmosphere containing $5 \% \mathrm{CO}_{2}$ in air at $37^{\circ} \mathrm{C}$ for a few days. Established cells, CHO-K1 cells were cultured in Ham's F12 medium, while HeLa cells were cultured in Eagle's MEM under the same condition as above. Some of these cells were cultured under experimental conditions such as cultures with the medium containing peroxisome proliferating agents, $0.2 \mathrm{mM}$ clofibrate or
$0.5 \mathrm{mM}$ bezafibrate, and some of them were labeled with ${ }^{14} \mathrm{C}$-bezafibrate, in case of hepatocytes. In case of CHO-K1 cells, they were cultured in a medium containing HRP (horse radish peroxidase, $1 \mathrm{mg} / \mathrm{ml}$ ) to induce pinocytosis. All the whole mount culture cells on grid meshes were prefixed in buffered $2.5 \%$ glutaraldehyde, stained with various histochemical reactions and postfixed in $1 \%$ osmium tetroxide. Then the whole mount culture cells were dried in a critical point drier (Hitachi HCP-1).

The histochemical reactions used were as follows.

1. Thiamine pyrophosphatase. Incubation in a medium containing thiamine pyrophosphate for $1 \mathrm{hr}$ at $37^{\circ} \mathrm{C}$, and substitution with cerium chloride (Novikoff and Goldfischer, 1961).

2. Glucose-6-phosphatase. Incubation in a medium containing $0.125 \%$ glucose- 6 -phosphate and $2 \%$ lead nitrate for $30 \mathrm{~min}$ at $37^{\circ} \mathrm{C}$, substituting with cerium chloride (Wachstein and Meisel, 1956; Tice and Barrnett, 1962).

3. Cytochrome oxidase. Incubation in a medium containing cytochrome $\mathrm{C}$ and $\mathrm{DAB}$ for $1 \mathrm{hr}$ at $37^{\circ} \mathrm{C}$, and substitution with cerium chloride (Seligman et al., 1968).

4. Acid phosphatase. Incubation in a medium containing sodium glycerophosphate and lead nitrate for 30 min at $37^{\circ} \mathrm{C}$, alnd substitution with cerium chloride (Mayahara and Chang, 1978). 
5. DAB reaction. Incubation in $\mathrm{DAB}$ (3,3'-diaminobenzidine tetrahydrochloride) solution for $10 \mathrm{~min}$ (Angermüller and Fahimi, 1981).

6. Radioautography. Cells were cultured in plastic Petri dishes (Falcon Plastic, CA, USA) containing formval and collagen coated gold meshes (Nisshin EM Co., Tokyo, Japan), in media containing radioactive compounds such as ${ }^{14} \mathrm{C}$-bezafibrate (Boehringer Mannheim GmbH, Germany) for 10 to $60 \mathrm{~min}$. After the labeling, cells were fixed, dehydrated in ethanol series and dried in a critical point dryer, coated with Konica NR-H2 emulsion according to a wire-loop method (Nagata, 1996), exposed for 4 months, developed in phenidone developer after GL latensification, stopped and fixed in an acid fixer, stained with lead citrate solution and dried (Nagata, 1996).

As thick sections, both rat and mouse liver tissues were used. The liver tissues were obtained from either normal or DEHP (diethyl-hexyl phthalate) containing diet for 1 or 2 weeks, prefixed in $2.5 \%$ glutaraldehyde solution in $0.1 \mathrm{M}$ cacodylate buffer for 1 hour, treated with $\mathrm{DAB}$ reaction and postfixed in $1 \%$ osmium tetroxide in the same buffer, embedded in Epok 812 resin (Oken Co., Tokyo, Japan). Semi-thin and thick sections at $0.1,0.2,0.5,1.0$ and $2.0 \mu \mathrm{m}$ thick were cut, picked up onto collodion coated copper grids (Nisshin EM Co., Tokyo, Japan), stained with lead citrate and were observed by high voltage electron microscopy.

After the histochemical reactions all the specimens were coated with thin layer of carbon and were observed in JEOL JEM-4000EX or Hitachi H-1250M high voltage electron microscopes at accerelating voltages of 400 or $1000 \mathrm{kV}$. Observing the specimens by tilting $\pm 8^{\circ}$, stereo-pair photographs were taken and were observed with stereoscopes to analyze the structure 3dimensionally. The pair of enlarged prints were observed with a stereoscope (stereo-viewer, Peak No. 1994-4, Peak Ltd. Tokyo, Japan). Some of the stereopairs were analyzed with an image analyzer (JEOLJIM5000), composing a stereo-color picture, taking a red picture from the right side and a green picture from the left side, which were observed with anaglyph type glasses (red/green or red/cyan glasses). Some of such stereo-color pictures were analyzed to plot contour lines from the two composed pictures at a thickness of $0.2 \mu \mathrm{m}$ depth, demonstrating both contour lines into one color picture.

\section{RESULTS}

The whole mount cultured cells stained with respective histochemical reactions as observed by high voltage electron microscopy at low power magnification revealed monolayered cells lining over grid meshes similarly to the light microscopy. When high power magnification photographs were taken after tilting \pm 8 and stereo-pairs were viewed with stereoscopes, cell organelles of cultured cells corresponding to the marker enzymes were 3-dimensionally observed (Figs. 1-3).

Thiamine pyrophosphatase reaction which demonstrated positive endproducts in Golgi apparatus could show contours of Golgi apparatus in primary cultured rat hepatocytes, which developed electron dense net-works in the perinuclear region of the hepatocyte cytoplasm surrounding the nucleus. Glucose6-phosphatase reaction which localized endoplasmic reticulum could show 3-dimensional structure of smooth surfaced endoplasmic reticulum well developed in the whole cytoplasm of the primary cultured rat hepatocytes (Fig. 1). Cytochrome oxidase demonstrated many filamentous or spherical mitochondria piling up each other disseminatedly in the whole cytoplasm of the hepatocytes. Acid phosphatase activity demonstrated small spherical lysosomes in the cytoplasm of hepatocytes. DAB reaction localized small peroxisomes disseminating in the cytoplasm of normal hepatocytes cultured in normal L-15 medium. However, when rat hepatocytes were cultured in a medium containing Clofibrate $(0.2 \mathrm{mM})$ in L-15 medium, which is one of the peroxisome proliferating agents, many peroxisomes positively stained with $\mathrm{DAB}$ reaction could be observed surrounding the nucleus, showing the proliferation of peroxisomes. These proliferating peroxisomes showed electron translucent vacuoles enveloped with limiting membranes and including electron dense $\mathrm{DAB}$ positive granules. On the other hand, when CHO-K1 cells, when they were stained with $\mathrm{DAB}$ reaction after culture with a medium containing HRP $(1 \mathrm{mg} / \mathrm{ml})$ for $48 \mathrm{hrs}$, the HRP particles incorporated into the cytoplasm by pinocytosis were positively stained with $\mathrm{DAB}$. The $\mathrm{DAB}$ positive electron dense pinocytotic vesicles could be seen throughout their cytoplasm. The relative relationship between the pinocytotic vesicles and the other cell organelles could be demonstrated 3-dimensionally with stereo-pairs.

Rat liver tissues, fed with DEHP containing diet for 2 weeks, fixed, stained with DAB, embedded and thick sectioned, revealed proliferation of electron dense peroxisomes in the cytoplasm surrounding the hepatocyte nuclei (Fig. 2). The 3-dimensional structure and relative relations between respective granules could be well observed by means of stereo-pairs. Using a pair of stereo-pair pictures (Fig. 2A, B), anaglyph type color 
pictures were composed (Fig. 2A) and the height of each structure at $0.2 \mu \mathrm{m}$ was measured and the contour lines were drawn with an image analyzer (JEOL JIM-5000). With this procedure, the height of each structure (Fig. 2B) could be measured exactly by measuring the distance of these two contour lines obtained from both right and left side stereo-pairs (Fig. 2C).

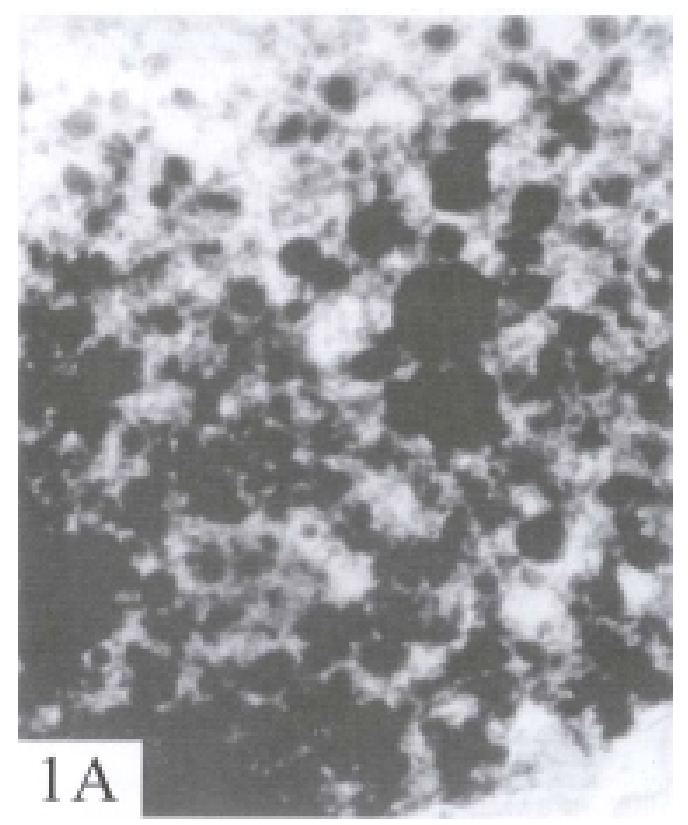

Radioautograms showing incorporation of 14Cbezafibrate into hepatocytes revealed that the silver grains due to the radioactivity were localized over the endoplasmic reticulum and peroxisomes, demonstrating the specific binding sites of this peroxisome proliferator (Fig. 3).

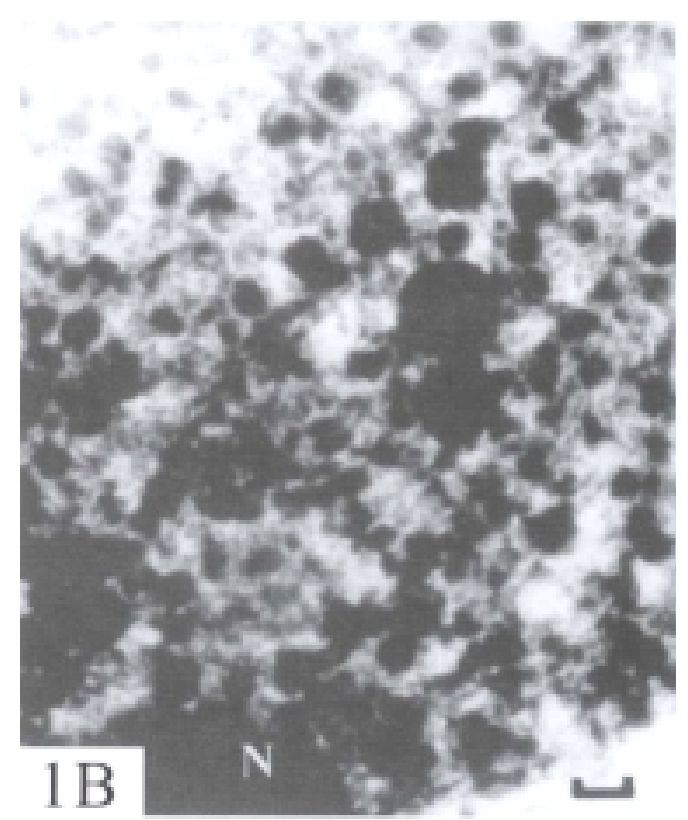

Fig. 1. High power stereo-pair electron micrographs (tilting $\pm 8^{\circ}$ ) of a rat hepatocyte, stained with glucose-6phosphatase reaction. Electron dense endproducts demonstrate cisternae of endoplasmic reticulum in the whole cytoplasm of the hepatocyte. $N$ : nucleus. Accerelating voltage at 1,000 kV. Scale bar $=1 \mu \mathrm{m}$.
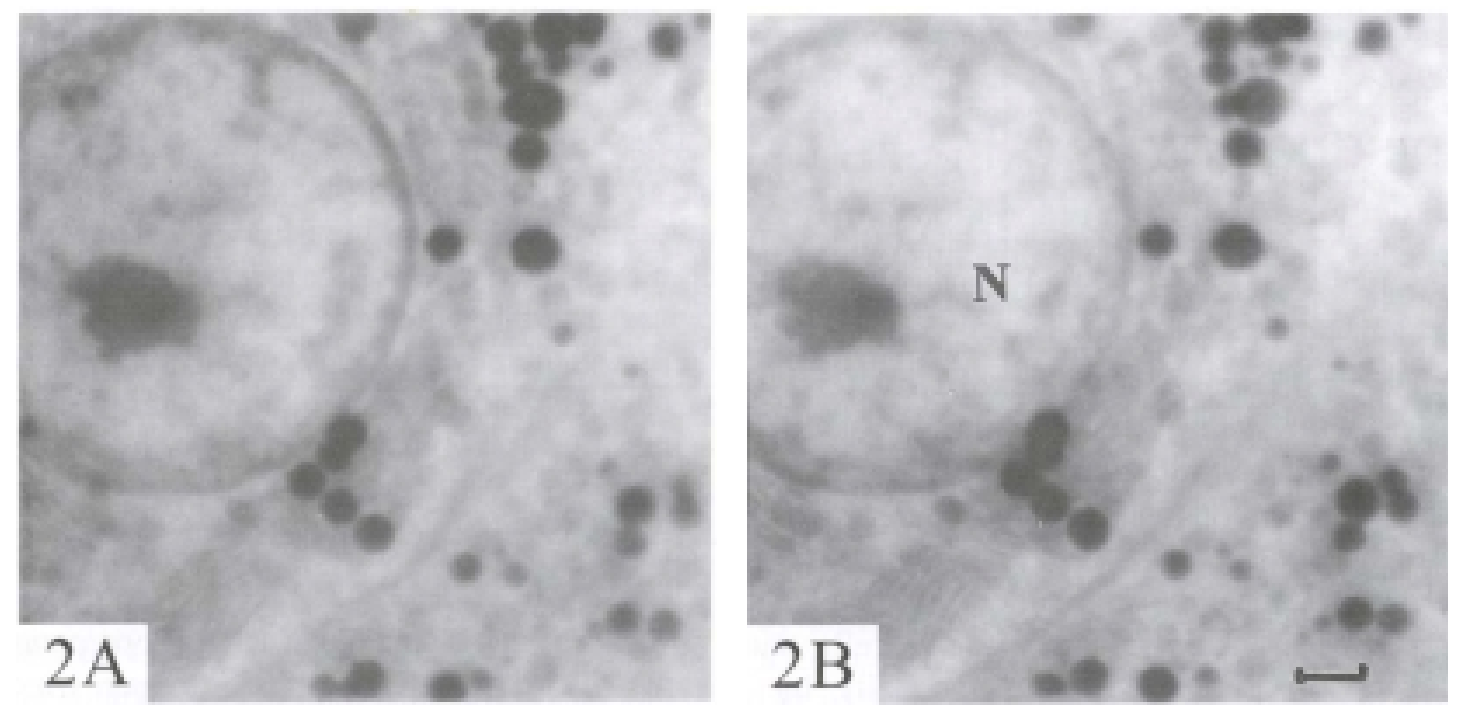

Fig. 2. High magnification stereo-pair electron micrographs (tilting $\pm 8^{\circ}$ ) of tissue section of rat hepatocyte, fed with 2\% DEHP for 1 week, stained with DAB reaction. Electron dense endproducts demonstrate proliferating peroxisomes while less dense structure are endoplasmic reticulum and mitochondria. N: nucleus. Accerelating voltage at 1,000 kV. Scale bar $=1 \mu \mathrm{m}$. 


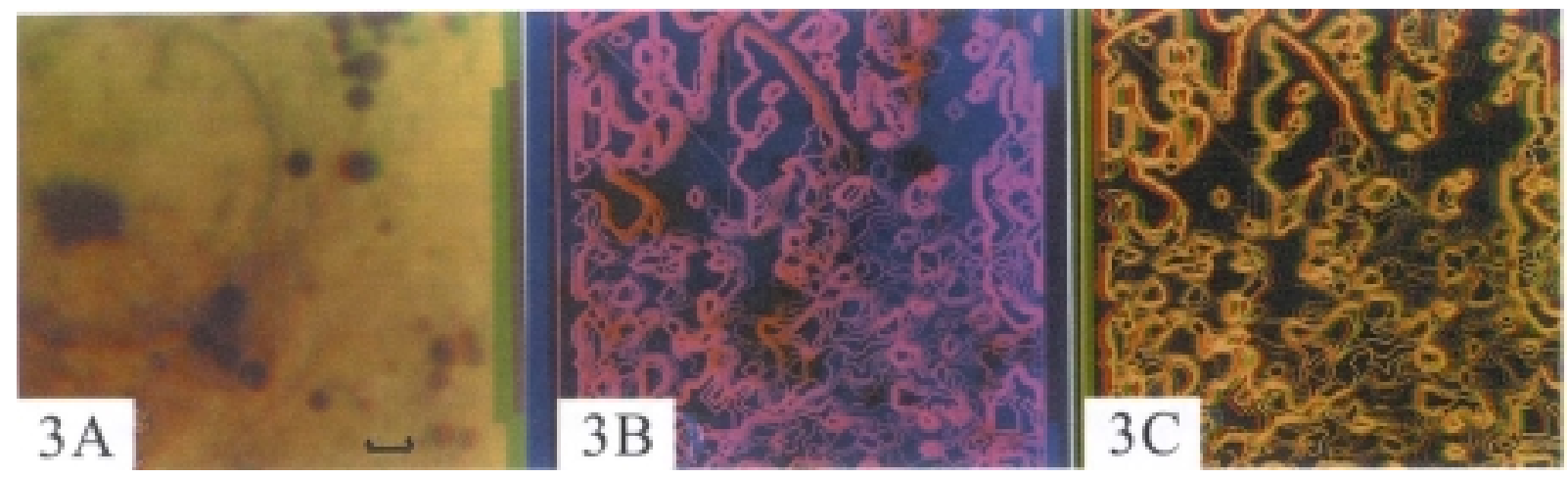

Fig. 3. Anaglyph type color pictures composed from the stereopairs in Fig. 2.

$3 A$. An anaglyph color picture composed of red (right, 2A) and green (left, 2B) pictures. 3B. An anaglyph type color picture composed of pink contour lines from the left side micrograph (2A) and a blue original picture from right (2B). 3C. An anaglyph color picture composed of red contour lines from left (2A) and green contour lines from right (2B). The distance between each line is $0.2 \mu \mathrm{m}$. Scale bar $=1 \mu \mathrm{m}$.
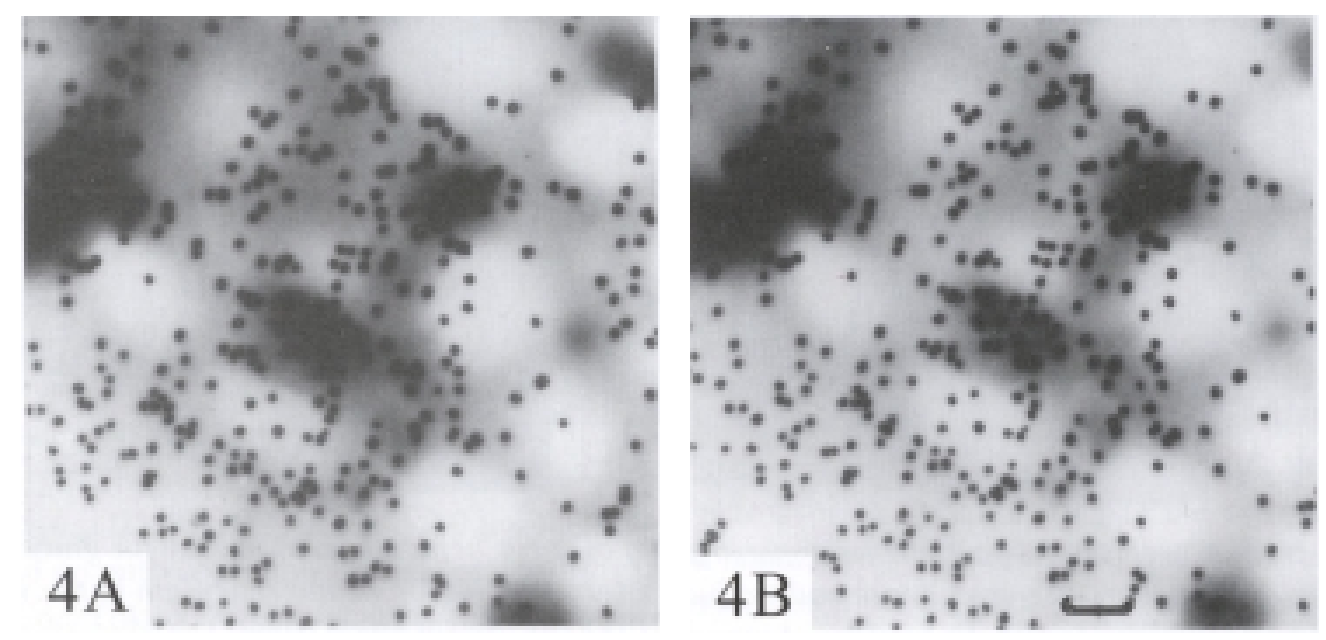

Fig. 4. High power stereo-pair electron micrographs (tilting $\pm 8^{\circ}$ ) of a rat hepatocyte, cultured in a medium containing ${ }^{14} \mathrm{C}$-bezafibrate and stained with DAB reaction. Electron dense silver grains are concentrating over less dense endoplasmic reticulum and dense peroxisomes, demonstrating the binding sites. Accerelating voltage at $1,000 \mathrm{kV}$. Scale bar $=1 \mu \mathrm{m}$.

\section{DISCUSSION}

From the results obtained, various kinds of cell organelles such as Golgi apparatus, endoplasmic reticulum, mitochondria, lysosomes, peroxisomes, pinocytotic vesicles which were stained with various histochemical reactions for marker enzymes such as thiamine pyrophosphatase for Golgi apparatus, glucose-6phosphatase for endoplasmic reticulum, cytochrome oxidase for mitochondria, acid phosphatase for lysosomes, $\mathrm{DAB}$ reaction for catalase in peroxisomes or for HRP in pinocytotic vesicles could be specifically stained in the whole mount cultured cells without sectioning and observed 3-dimensionally by high voltage electron microscopy. This procedure should be very useful in analyzing 3-dimensional structures of these cell organelles as well as to localize 3-dimensional relationship between these cell organelles.
Observation of whole mount cells was first used by Porter et al. (1945) when they tried to observe thin cytoplasmic process of cultured cells without sectioning at the initial stage of electron microscopy applied to biological materials when the ultramicrotomes were not available and there was no way to obtain thin sections. However, once the ultramicrotomes were developed and ultrathin sections were used for electron microscopic observation, such method to observe whole mount culture cells were not used at all during the period of 1950 s to 1970 s.

The second stage to employ such thick preparations as whole mount cultured cells were again tried by Buckley and Porter (1975) or Wolosewick and Porter (1975, 1976, 1977, 1979) for the purpose of observing the cytoskeleton of the whole cells by high voltage 
electron microscopy. Buckley and Porter (1975) first used whole mount cultured cells after drying them by critical point drying which was formerly used in preparing specimens for scanning electron microscopy. We used the same technique to observe the histochemical reactions in cultured cells by observing the marker enzymes or radioautographic reactions by high voltage electron microscopy at $400-1,000 \mathrm{kV}$ (Nagata et al., $1977,1984,1986,1987,1990)$, as was reviewed by Nagata $(1984,1995,1997)$.

The procedures preparing thick specimens such as whole mount cultured cells or thick sections obtained from embedded tissues which were stained with histochemical reactions or radioautographed with RIlabeled precursors demonstrating specific cell organelles are a litle complicated as compared with the other routine procedures in preparing ultrathin sections. However, we are able to obtain more information by observing such specimens by high voltage electron microscopy at accerelating voltages of $400-1,000 \mathrm{kV}$ and this procedure should be very useful tool in analyzing the 3-dimensional structures of these cell organelles.

\section{CONCLUSIONS}

The methods preparing thick specimens from whole mount cultured cells, lining over grid meshes and staining with various histochemical reactions, dried with critical point dryers or thick sections from embedded tissues and observing them by high voltage electron microscopy at accerelating voltages of $400-1,000 \mathrm{kV}$ and analyzing the intracellular localization and ultrastructure of cell organelles with stereo-pair pictures should be very useful to understand 3-dimensional structures of cell organelles as well as the 3-dimensional relationship between them.

A preliminary report of some of the data (Nagata, 1999) has been presented at the $X^{\text {th }}$ International Congress for Stereology, Melbourne, Australia, 1-4 November 1999.

\section{ACKNOWLEDGMENTS}

The author thanks to Dr. T. Arii, Department of High Voltage Electron Microscopy, National Institute for Physiological Sciences, Okazaki National Research Institutes, Okazaki, Japan for providing the facilities using Hitachi H-1250 high voltage electron microscope and to Mr. K. Kametani, Electron Microscopy Laboratory, Shinshu University School of Medicine, Matsumoto, Japan for technical assistance during the course of this study.
This study is partly supported by a grant for characteristic research and education from the Japan Foundation for Promotion of Private Schools provided to the author.

\section{REFERENCES}

Angermüller S, Fahimi HD (1981). Selective cytochemical localization of peroxidase, cytochrome oxidase and catalase in rat liver with 3,3'-diamino-benzidine. Histochemistry 71:33-44.

Buckley IK, Porter KR (1975). Electron microscopy of critical point dried whole cultured cells. J Microsc 104:107-20.

Mayahara H, Chang JP (1978). Electron microscopic study of acid phosphatase activity in cultured human cystic fibrosis fibroblasts. Acta Histochem Cytochem 11:449-59.

Nagata T (1984). High voltage electron microscopic observation on whole mount preparation of cultured cells. A review on trend and prospect. Tissue Culture (Tokyo) 10:411-3.

Nagata T (1995). Three dimensional observation of whole mount cultured cells stained with histochemical reactions by ultrahigh voltage electron microscopy. Cell Mol Biol 41:783-92.

Nagata T (1996). Techniques and applications of electron microscopic radioautography. J Electron Microscopy 45:258-74.

Nagata T (1997). Three dimensional observations on whole mount cultured cells and thick sections stained with hitochemical reactions by high voltage electron microscopy. In: Motta PM, ed. Recent Advances in Microscopy of Cells Tissues and Organs. Rome, Italy: Antonio Delfino Editore, 37-44.

Nagata T, Murata K, Yoshida S, Ohno S, Iwadare N (1977). Whole mount radioautography of cultured cells as observed by high voltage electron microscopy. Proc Fifth Internat Conf High Voltage Electron Microsc 347-50.

Nagata T, Usuda N (1984). Application of histochemistry to whole mount preparations of cultured cells. Tissue Culture 10:428-33.

Nagata T, Usuda N, Ma H (1986). Applicationof high voltage electron microscopy to histochemistry of whole mount preparations of cultured cells or thick sections from embedded tissues. Proc XIth Internat Cong Electron Microsc 2:1183-4.

Nagata T, Usuda N, Ma H (1990). Use of thick histochemical preparations, whole mount cultured cells or thick sections from embedded tissues, for three-dimensional observation by ultrahigh voltage electron microscopy. Proc XIIth Internat Cong Electron Microsc, Peachy LD, Williams DB. ed. San Francisco: San Francisco Press, 3:184-5.

Nagata T, Usuda N, Maruyama M (1987). Observation on histochemical preparations of whole mount cultured cells by means of high voltage electron microscopy. J Clin Electron Microsc 20:681-2. 
Novikoff AB, Goldfischer S (1961). Nucleosidediphosphatase activity in the Golgi apparatus and its usefulness for cytological studies. Proc Natl Acad Sci USA 47:802-10.

Porter KR, Claude A, Fullam ER (1945). A study of tissue culture cells by electron microscopy. Methods and preliminary observations. J Exp Med 81:233-46.

Seligman AM, Karnovsky MJ, Wasserkrug HL, Hanker JS (1968). Nondroplet ultrastructural demonstration of cytochrome oxidase activity with a polymerizing osmiophilic reagent, diaminobenzidine (DAB). J Cell Biol 38:1-14.

Tice LW, Barrnett RJ (1962). The fine structural localization of glucose-6-phosphatase in rat liver. J Histochem Cytochem 10:754-62.
Wachstein M, Meisel E (1956). On the histochemical demonstration of glucose-6-phosphatase. J Histochem Cytochem 4:592.

Wolosewick JJ, Porter KR (1975). High-voltage electron microscopy of WI-38 cells. Anat Rec 181:511-2.

Wolosewick JJ, Porter KR (1976). Stereo high-voltage electron microscopy of whole cells of the human diploid line, WI-38. Amer J Anat 147:303-24.

Wolosewick JJ, Porter KR (1977). Observations on the morphological heterogeneity of WI-38 cells. Amer J Anat 149:197-226.

Wolosewick JJ, Porter KR (1979). Microtrabecular lattice of the cytoplasmic ground substance. Artifact or reality. J Cell Biol 82:114-39. 